\title{
E-Lancing: Killing two Birds with One Stone
}

\author{
Belal Shneikat \\ Assistant Professor in Business Administration \\ University of Kyrenia \\ Kyrenia/ North Cyprus via Mersin 10, Turkey
}

\begin{abstract}
The paper highlights the importance of controlling the e-lancing websites by governments to cut the unemployment insurance being paid to individuals who are working as e-lancers while benefitting from the insurance simultaneously. In addition, Governments should consider imposing taxes on e-lancing websites because that will increase tax revenues. Hence, two birds could be hit with one stone!. The literature review reveals that e-lancing has become one of the vital sources for finding project based jobs in both developed and developing countries and scholars expect this trend to go on in the future. Two propositions are suggested and discussions \& implications are presented.
\end{abstract}

Keywords: E-lancing, Unemployment Insurance, Taxes

\section{Introduction}

Outsourcing transfers some resources and activities that have been done internally to external vendors (Heizer \& Render, 2006; Wasner, 1999). Outsourcing represents a continuous trend that aims to utilize the efficiency that is generated from specialization (Heizer \& Render, 2006). The outsourced service is performed by an expert who is specialist in that accurate specialty (Heizer \& Render, 2006). Outsourcing lets firms focus on the critical factors of success. These critical factors enable the firm to get the competitive advantage (Broedner et al., 2009; Kroes \& Ghosh, 2010).According to Heizer and Render (2006) the outsourced resources include people, facilities, and equipment. Firms outsource their legal functions, accounting work, information technology requirements, product assembly, and logistics. Moreover, Von Corswant and Fredriksson (2002) stated that outsourcing includes manufacturing. Jensen and Pedersen (2011) and Martínez-Noya et al., (2012) proposed that it involves R\&D. Irina et al., (2012) stated that it includes logistics. Unal and Donthu, (2014) proposed sales. Carbone, (1996) suggested procurement. Belcourt (2006) and Caruth et al., (2013) posited that it includes human resources. Some companies such as Nike outsources all activities related to the shoe manufacturing (Leavy, 2005). In general, the main candidates for outsourcing are these activities that can be electronically transferred because of the low cost of transferring electronic data throughout the globe.

The decision to insource or outsource relies on the relative costs, more precisely long-term costs (Beaumont \& Sohal, 2004). In general, organizations are obliged to outsource some activities (e.g. they depend on suppliers to get water and electricity). But, at the same time, they insource other activities such as employee appraisal. On the other hand, offshoring is considered to be a new type in the global trade (Egger, Kreickemeier \&Wrona, 2015). Some scholars such as (Lewin, Massini, \& Peeters, 2009) defined off shoring as the process of coordinating and outsourcing business functions and tasks across national borders. International outsourcing is considered to be off shoring (Musteen, 2016). Similarly, Burke and Ng (2006) stated that off shoring is considered to be a synonymous term to outsourcing with one difference that is off shoring requires the outsourced service/good to be sent abroad.

Outsourcing is considered as a good way to solve business problems and a lot of reports propose increasing use of it (Beaumont \& Sohal, 2004). Outsourcing initially used in the IT sector, but now many business activities are outsourced (Beaumont \& Sohal, 2004). Lonsdale and Cox (2000) have noted that outsourcing market is difficult to be estimated but it is still growing. The outsourcing market in the USA reached \$340Billion in 2000 after it was \$295B in 1999 (Casale, 2000). In order to outsource and offshore some services effectively, firms look for hiring internet freelancers (e-lancers) who work online to perform some tasks/projects for these companies. According to research firm "IDC", bout 850 million of the world workforce will work via mobile technology and/or remote aaccess (Schweyer, 2006 as cited in Abubakar \& Shneikat, 2017). 
Some e-lancing websites such as "elance-odesk.com" shows that countries such as the USA, UK and Canada are among the top earning countries from e-lancing with a growth rate ranged between $10 \%$ to $25 \%$. These countries have a scheme to pay the unemployment insurance for citizens who have lost their jobs (Cerda \& Vergara, 2008). Because these countries don't control the online marketplaces ( e-lancing websites), some people who benefit from the unemployment insurance might work as e-lancers and therefore, this research tries to shed light on two issues: First, governments should have more control on online marketplaces in order to identify the genuine identity of elancers because they usually use a nickname while working on these websites and just the website itself knows the real identity of that e-lancer. The employer (also is given a nickname by the website) pays for the website which in turn pays for the e-lancer. So, if the government knows who are the e-lancers, they will stop paying him/her the unemployment insurance. At the same time, governments can impose taxes on the transactions being made on these websites and that will increase the revenues. Hence, governments by controlling e-lancing websites can hit two birds with one stone

\section{Theoretical Underpinnings}

Internet has created opportunities to people to work online for employers who are thousands of kilometers away. Elancing "online marketplace" is a website where employment seekers meet employers to perform some type of work (Abubakar \& Shneikat, 2017). Firms find difficulties in firing and hiring employees due to legal issues and initial costs (Abubakar \& Shneikat, 2017). This led to the emergence of e-lancingthat provides IT (Malone \& Laubacher, 1998) and other forms of services. E-lancing enables firms to efficiently outsource projects (Snir \& Hitt, 2003) to e-lancers who look for performing tasks/projects online. Currently, There are three billion people who use internet (Lehdonvirta et al.,2015). These people use different methods such as pay by hour, mobile, or domestic connectivity to be connected directly to the internet. This connectivity has given the online workers from many countries a direct access to the global demand which usually originates from high income countries such as the USA and Canada (Thabassum, 2013). Raja et al. (2013) stated that global demand ushers a hope that the world might have a new age of international service trade. This new age has enabled all parties to be connected with each other easily and facilitated the flow of goods and services from manufacturers to customers. Online marketplaces are websites that enable job seekers to be connected with distant employers who offer temporary work. Online marketplaces allow local employees to market their skills and knowledge to the foreign employers and getting foreign wages (Lehdonvirta et al., 2015). In recent years, some online marketplaces have grown rapidly. Lehdonvirta et al. (2015) stated that on oDesk.com (currently upwork.com) the total number of hours worked in the first quarter of 2013 exceeded 10 million, while it was just 2 million in the first quarter of 2010. Moreover, the total earnings on the same website reached \$1 billion in 2012 (Lehdonvirta et al., 2015). In 2014, it exceeded \$3billion (elance-odesk.com).

From e-lancers perspective, they engage in e-lancing due to different motivations such as Work-family balance, flexibility \& Autonomy, economic incentives \& low barrier of entry, opportunity to develop one's creative skills, trust \& guarantee of payment after work, and unemployment, equality, and disability (Abubakar \&Shneikat, 2017). Hence, the economic factors play a vital role in attracting people to engage in eLancing especially from the developed countries. According to (elance-odesk.com) some developed countries such as the USA and UK were among the top earning countries from eLancing with a growth rate of $25 \%$ in 2014 compared to 2013. This growth rate should attract attention from governments in the western countries to have more control over these websites to see who is generating income from these websites and therefore, the government should cut the unemployment insurance being paid to those e-lancers. Based on the above mentioned, the following proposition is suggested:

Proposition1. The government's overseeing on e-lancing websites will help in cutting or reducing the unemployment insurance being paid to e-lancers.

Some European countries such as France and Germany proposed tax blitz on American tech giants like Amazon and Google (Brunsden \& Khan, 2017). This suggestion shows the European intention to fight multinational tax avoidance. Although some US technology companies such as Facebook and Apple are taxed in Europe (Brunsden \& Khan, 2017), online marketplaces still enjoy zero taxes on their revenues and/or profits. That makes government's loose potential taxes. Hence, the following proposition is suggested: Proposition 2: The government's overseeing on e-lancing websites will help in increasing the tax revenues. 


\section{Discussion and conclusion}

This paper shows the importance of controlling the online marketplaces to cut the unemployment insurance paid to e-lancers who enjoy getting wages from online marketplaces simultaneously. In addition, when governments control these marketplaces, they can impose taxes on transactions being done. Currently, There are three billion people who use internet (Lehdonvirta et al.,2015). These people use different methods such as pay by hour, mobile, or domestic connectivity to be connected directly to the internet.

This connectivity has given the workers from many countries especially south- East Asia a direct access to the global demand which usually originates from high income countries such as the USA and Canada (Thabassum, 2013). The USA leads hiring countries, followed by the UK, France, Germany, Israel, Netherlands, Singapore, and Switzerland. The rate of growth in these countries was more than $25 \%$ in 2014 . While it was between $10-25 \%$ in the same year in Australia and Canada (elance-odesk.com). For the top earning countries, the USA, Philippines, Russia, Bangladesh, The UK, and Romania got a growth rate of more than $25 \%$ in 2014 compared with 2013. India, Ukraine, Pakistan, and Canada their growth rate was between $10-25 \%$ in the same year (elance-odesk.com). Online marketplaces allow local employees to market their skills and knowledge to the foreign employers and getting foreign wages (Lehdonvirta et al.,2015).

In recent years, some online marketplaces have grown rapidly. Lehdonvirta et al. (2015) stated that on oDesk.com (currently upwork.com) the total number of hours worked in the first quarter of 2013 exceeded 10 million, while it was just 2 million in the first quarter of 2010. Moreover, the total earnings on the same website reached $\$ 1$ billion in 2012 (Lehdonvirta et al., 2015). However, the total earnings on elance and odesk exceeded \$3Billion in 2014. These numbers show that the market size of e-lancing is increasing sharply. And this why governments should pay attention to these websites and how much they can earn taxes from these websites or how much these can save if they stop paying the unemployment insurance to those e-lancers

\section{References}

Abubakar, A.M., \& Shneikat, B.H.T. (2017) eLancing motivations. Online Information Review, 41(1), 53-69.

Brunsden, J.,\& Khan M. (2017, September 9). France drive EU tax blitz on revenues of US giants. Retrieved from the Financial Times.

Cappelli, P. (1999). The New Deal at Work. Boston, MA: Harvard Business School Press.

Cascio, W.F. (2006). Managing human resources: Productivity, quality of work life, profits. Burr Ridge, IL: McGraw-Hill/Irwin.

Cascio, W.F., \& Aguinis, H. (2008). 3 Staffing Twenty-first-century Organizations. The Academy of Management Annals, 2(1), 133-165

Cerda, R., \& Vergara, R. (2008). Government Subsidies and Presidential Election Outcomes: Evidence for a Developing Country. World Development, 36(11), 2470-2488.

Coleman, J. (1993). The Rational Reconstruction of Society. American Sociological Review, 58(1), 1-15

Dong, A \& Pourmohamadi, M. (2014). Knowledge matching in the technology outsourcing context of online innovation intermediaries. Technology Analysis \& Strategic Management, 26(6), 655-668.

Engardio, P. (2006). The future of outsourcing. Business Week, 50-58

Hamm, S. (2006). Speed demons. Business Week, pp. 67-76

Nilles JM. (1975). Telecommunications and organizational decentralization. IEEE Transactions On CommunicationsCom, 23, 1142-1147.

Schweyer, A. (2006, October 17). Managing the virtual global workforce. Human Resources (Australia).RetrievedApril12,2007, Retrived from http://www.humanresourcesmagazine.com.au/. 